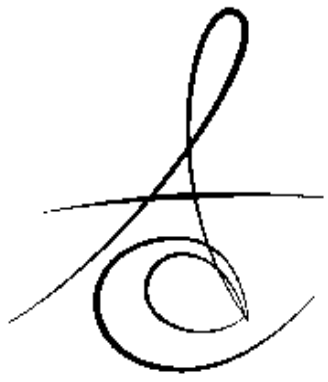

Yrd. Doç. Dr. Nilay ER*

Dr. F. Gülfeşan ÇANAKÇi ${ }^{* *}$

\section{DİŞ HEKİMLİĞínDE PERİFERİK SİNİR YARALANMALARI VE TEDAVİsí}

PERIPHERAL NERVE INJURY AND TREATMENT IN DENTISTRY

Makale Kodu/Article code: 2254

Makale Gönderilme tarihi: 24.04.2015

Kabul Tarihi: 19.08 .2015

\author{
Yrd. Doç. Dr. Gonca D.ÇAPAR* \\ Prof. Dr. Alper ALKAN ${ }^{* * *}$
}

\section{öz}

Diş hekimliğinde periferik sinir yaralanmaları, rutin işlemler sırasında, cerrahi uygulamalarda veya travma sonucunda sıklıkla karşılaşılan olgulardır. Sinirin yapısı ve sinir hasarı mekanizmaları konusunda bilgi sahibi olmak, doğru teşhis ve tedavi için oldukça önemlidir. Sinir yaralanmalarının tedavisi, temel olarak medikal tedavi ve cerrahi tedavi olarak ikiye ayrılır. Medikal tedavinin sonuç vermediği hastalarda, muhtemel cerrahi tedavi için seçenek ve sonuçlarını bilmek, bu kritik komplikasyonda, doğru zamanlama ve uygulama açısından büyük önem arz etmektedir. Bu derlemenin amacı; diş hekimliği klinik uygulamalarında karşılaşılabilecek periferik sinir yaralanmaları sebeplerini hatırlamak ve mevcut kitap bilgileri ile güncel literatür bilgilerini harmanlayarak bu önemli komplikasyon hakkında bilgi sahibi olmaktır.

Anahtar kelimeler: diş hekimliği; medikal tedavi; periferik sinir yaralanması; sinir cerrahisi

\section{GİRİş}

Sinir sistemi iç ve dış ortamda oluşan değişikliklere ani yanıtın oluşturulduğu sistemdir. İç ortamda oluşan değişiklikleri düz kas, kalp kası ve salgı bezlerine gönderdiği emirlerle düzenleyip kontrol ederken; dış ortamda oluşan değişikliklere iskelet kaslarına emir göndererek yanıt verir. ${ }^{1}$ İnsan vücudunda, sinir sistemi; merkezi sinir sistemi (MSS) ve periferik (çevresel) sinir sistemi (PSS) olarak iki kısımda incelenir.

PSS'yi oluşturan sinirler horizontal kesitte içten dışa doğru incelendiğinde en dışta arter, ven ve lenfa-

\section{ABSTRACT}

Peripheral nerve injuries are frequently seen during routine procedures, surgical operations or after traumas in dentistry. Knowledge about the structure of the nerve tissue and nerve damage mechanisms is important for accurate diagnosis and treatment. Management of nerve injury is basically divided in two as medical and surgical treatment. It has a great importance to be aware of surgical treatment options and their possible results for correct timing and treatment in patients who do not respond to medical therapy. The purpose of this review is to to have information about peripheral nerve injuries and recent treatment approaches in clinical dental practice combining the book information and current literature. Key words: dentistry; peripheral nerve injury; medical treatment; surgical treatment

\footnotetext{
*Trakya Üniversitesi Diş Hekimliği Fakültesi, Ağız Diş ve Çene Cerrahisi AD

${ }_{* * *}^{*}$ Kahramanmaraş Ağız ve Diş Sağlığı Merkezi,

*** Erciyes Üniversitesi Diş Hekimliği Fakültesi, Ağız Diş ve Çene Cerrahisi AD
}

tiklerin bulunduğu gevşek yapısı ile siniri dış etkenlere karşı koruyan epinöriyum tabakası görülür. Hemen altındaki perinöriyum, fasikül adı verilen akson demetlerini saran kuvvetli bir bağ dokusu olup, travma ve iskemiye karşı çok dayanıklıdır ve bu bariyerin bozulması halinde sinir iletimi önemli ölçüde etkilenir. Endonöriyum ise sinir liflerini çevreleyen gevşek bağ dokusu olup, içerisinde aksonlar, Schwann hücreleri, kollajen lifler, fibroblastlar, kapiller damarlar ve az sayıda mast hücresi ile makrofajlar vardır. Fasikül ise periferik sinirin en küçük anatomik birimi olup, cerrahi olarak diseke edilebilir ve görülebilir. ${ }^{2}$ 
Diş hekimliği; tedavilerin girişimsel bir yöntemle yapıldığı ve hemen hemen her işlemde dental anestezi uygulandığı düşünüldüğünde sinir yaralanmaları açısından önem taşıyan bir branştır. Bu makalenin amacı diş hekimliği kliniğinde PSS'de yaralanmaya yol açan nedenleri ve tedavi seçeneklerini literatür bilgileri eşliğinde değerlendirmektir.

\section{Sinir yaralanmalarının sınıflandırılması}

Sınıflandırma, hekimin teşhis koymasına, tedavi planı oluşturmasına, cerrahi tedavinin zamanlamasına karar vermesine ve yaralanmanın prognozunu hesaplamasına yardımcı olur. PSS'de yaralanmalar sinir dokusunun etkilenme derecesine göre Seddon ve Sunderland tarafından iki şekilde sınıflandırılmıştır, günümüzde de bu sınıflandırmalar halen geçerliliğini korumaktadır (Tablo 1). ${ }^{3,4}$

Tablo 1. Periferik sinir yaralanmalarında Seddon ve Sunderland sınıflandırmaları.

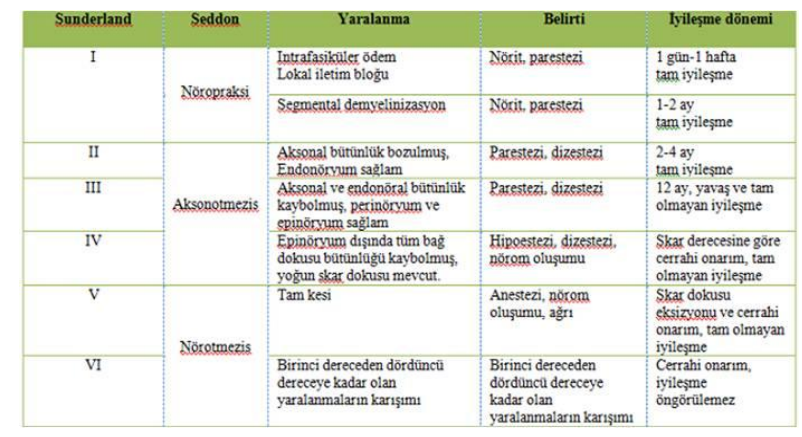

\section{Diş Hekimliğinde Sinir Yaralanması Nedenleri}

Lokal anestezi: İğne ile direkt temas, hematom oluşumu veya lokal anestezik maddenin kimyasal etkisi ile oluşabilir. ${ }^{5}$

Gömülü diş çekimi: Özellikle alt gömülü 20 yaş dişi çekimi sırasında inferior alveolar sinir hasarı sık karşılaşılan ve istenmeyen önemli bir komplikasyondur. Alt çenede bukkal mukoperiostal flebin kaldırılması sırasında mental sinir hasarı oluşabilmekte, üst çenede palatal flap elevasyonu sonucu naso-palatin sinir yaralanabilmektedir. ${ }^{6,7}$

Ortognatik cerrahi: Ortognatik cerrahide ve distraksiyon osteogenezisi işlemlerinde direkt travma ile sinir hasarı oluşabildiği gibi cerrahi işlem sırasında oluşan germe ve çekme kuvvetleri veya operasyon sonrası oluşan ödemin baskısı ile de sinir hasarı meydana gelebilmektedir. ${ }^{7,8}$ Cerrahi girişim sırasında yapılan ekartman ile oluşan ılımlı çekilme yaralanmaları genelde iyi prognozludur.

Maksillofasiyal Travma: Sinir hasarı, yaralanmanın tipine, kırık mevcudiyetine ve bölgedeki sinirin etkilenme derecesine göre çeşitlilik gösterir. Uygun ve Apaydın yaptıkları derlemede çene yüz bölgesine gelen travma sonucu oluşan mandibula kırıklarının \%8 ile \%66.7' sinde, orta yüz kırıklarının \%15-46'sında sinir hasarı olabildiğini bildirmişlerdir. ${ }^{7}$ Bunun dışında ezilmelerde, damar basısı yapan kırıklarda ve antikoagülan kullanımında periferik sinirlerde iskemik hasar görülebilir.

Endodontik tedavi: Kök kanalının taşkın şekillendirilmesi sonucu oluşan mekanik travma, apikalde taşkın dolgu sonucu oluşan basınç, kök-kanal yıkama solüsyonlarının toksik etkisi, mandibulada apikal foramneden taşılarak inferior alveolar kanal içine dolgu maddesi gönderilmesi literatürde en sık karşılaşılan endodontik sinir yaralanmalarıdır. ${ }^{9-12}$

İmplant cerrahisi: İmplant uygulaması sırasında inferior alveolar kanala olan mesafe düzgün hesaplanmadığı takdirde, gerek kemik preperasyonu gerekse implant yerleştirilmesi sırasında sinire temas edilebilir ve hasar meydana gelebilir. ${ }^{13}$

Temporomandibular eklem (TME) cerrahisiArtroskopi: TME cerrahisi sırasında fasiyal sinir hasa$\mathrm{rI}^{14}$, artroskopi sırasında da auriculotemporal sinir hasarı oluşabilmektedir. ${ }^{15}$

\section{Klinik Hassasiyet Testleri}

Hastanın uyarana verdiği yanıtı mümkün olduğunca objektif olarak değerlendirmek üzere uygulanan bu testlerde hastaların gözleri kapalıdır ve verilen cevap, cevaptaki gecikme, ağrılı uyarana verilen cevap, karşı tarafla kıyaslanarak belirlenir ve rapor edilir.

Hafif temas testi: Dikiş ipliği ile etkilenen bölgeye hafif dokunuşlar yaparak hastanın algısı ve hassasiyeti not edilir. ${ }^{16}$

İki noktalı ayırım testi: Etkilenen tarafta ve karşı tarafta iki nokta belirlenerek künt el aletleri ile bir $\mathrm{mm}$ derinliğinde baskı oluşturularak, iki nokta temasını da hissedip hissetmediğine bakılır. Hissedilen noktalar arası mesafe not edilir ve sonraki seanslarda mesafe farkı oluşup oluşmadığı değerlendirilir. ${ }^{17}$

Von-frey monofilamentler: Yumuşak fırça darbeleriyle hastanın temas algısını ölçmede kullanılırlar. ${ }^{18}$

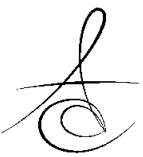


Pinprick testi: 22 veya 23 gauge iğne ile ağrıya cevap ölçülür. ${ }^{19}$

Termal test: Radyan ISI kaynağı veya etil kloritli pamuk parçası, mümkün olduğunca çabuk deriye değdirilir ve tepki ölçülür. ${ }^{20}$

Tat duyusu testi: Tatlı, tuzlu, ekşi ve acı yiyecekler verilerek ayırt etmesi istenir. ${ }^{21}$

\section{Periferik Sinir Yaralanmalarında Görüntüleme}

Periferik sinir yaralanmalarını görüntülemek için direkt radyografi, bilgisayarlı tomografi (BT) ve magnetik rezonans görüntülemesi (MRG) sıklkkla kullanılmaktadır. Direkt grafiler genel olarak sinir dokusunun yapısından ziyade fraktürlerin, yabancı cisim ve lokal lezyon bölgesinin değerlendirilmesinde kullanılır. BT ve MRG periferik siniri çevre yapılardan ayırt etme ve çözümlemede bazı yetersizliklere sahip olduğu için MR nörografi tekniği (MRN) geliştirilmiştir. ${ }^{22} \mathrm{MRN}$, boyun ve ekstremitede normal ve anormal yapıdaki periferik sinirlerin gerçek şekilde görüntülenmesin sağlar. Özellikle travmatik lezyonların ayırdedilmesinde yararlıdır. ${ }^{22}$

\section{SÍNİR TAMİRI \\ Medikal Tedavi}

Medikal tedavinin amacı zedelenen sinirlerin fonksiyonlarını geri getirmek ve hastaların yaşam kalitesini artırmaktır. ${ }^{23}$ Medikal tedavide ilk seçenek olarak kortikosteroidler değerlendirilir. Kortikosteroidler; doku şişmesini ve enflamasyonu azaltarak sinir dokusu üzerindeki basıyı ortadan kaldırılar, ayrıca kortikosteroid kullanımının sekonder yaralanmayı azaltabileceği ve membran stabilize edici etkisi ile normal homeostazı sağlayabileceği düşünülmektedir. ${ }^{7}$ Seo ve ark. sagital split osteotomisi uygulanan 27 hastada steroid kullanımının etkisini değerlendirmişler ve ameliyattan bir hafta sonra başlanan prednisolonun iki hafta boyunca azalan dozlarda kullanıldığı takdirde antienflamatuar etkisi, ödemi azaltması ve sinir büyüme faktörü salgılayarak akson rejenerasyonuna katkıda bulunması sayesine sinir iletimi sağlamada etkin olduğunu bulmuşlardır. ${ }^{24}$ Analjezik ilaç kullanımı sinir yaralanmalarına bağlı ağrıların kontrol edilmesinde hastalara yardımcı olur. ${ }^{23}$ Antiviral ajanlar, sinir yaralanmasının etyolojisinde bir faktör olan endonöral ödemi azaltmaya yardım ederler. ${ }^{25}$ Hiperbarik oksijen (HBO) ise, akut travmatik yaralanmalarda yardımc endo- nöral ödem ve kapiller damarlardaki basınc riskini azalttığı bildirilmiştir. ${ }^{26}$ Toros ve ark. Yayınla- dıkları hayvan deneyinde fasiyal sinir yaralanmalarında hiperbarik oksijen ve metilprednizolonun birlikte kullanılmasının, ayrı ayrı kullanımlarına göre daha başarılı sonuç verdiğini göstermişlerdir. ${ }^{27}$

\section{Cerrahi Tedavi}

Periferik sinir yaralanmaları sonucunda; sinirin tam kesisi, dört aydan fazla süren anesteziler veya hipoestezilerin gelişme göstermemesi durumunda cerrahi endikasyon düşünülür. ${ }^{7}$

\section{Cerrahi Tedavi Evreleri}

Siniri açığa çıkarma²: Lingual veya inferior alveolar siniri açığa çıkarma işlemi, fasiyal veya oral yolla gerçekleştirilebilir. Mental sinire, bukkal sulkusa yapılan insizyon yoluyla ulaşılır. İnfraorbital sinire ise; intraoral olarak maksiler labiobukkal vestibülden, ekstraoral olarak subsiliar bölgeden insizyonla ulaşılabilir.

Nöroliz: Sinirin çevredeki yapışıklıklardan serbestleştirilmesi işlemidir. Şiddetli yaralanmış sinirler bir sinir greftine gereksinim duyabilir. ${ }^{2}$ İnferior alveolar sinirin eksternal nörolizi için genellikle modifiye bukkal kortikotomileri veya tek taraflı sagital split osteotomisini içeren kortikotomi gerekir. Lingual sinirin açığa çıkarılması ise 3. molar cerrahisinde kullanılan insizyonun modifiye edilerek daha lingualde yapılması ile elde edilir. 2,28

Sinir ucu preperasyonu: Cerrahi işlemin en kritik noktası, özellikle sinir kesilmesinden dolayı ayrıma olduğunda proksimal ve distal uçları gözlemlemektir. ${ }^{2}$ Eksizyon, mantar şeklindeki fasiküller görünene kadar yapılmalı, fazla doku kaldırımamalıdır.

Anastomoz - Nörorafi: Sinirin direkt olarak uç uca bağlanmasıdır. Periferik sinir onarımında, uç uca onarım altın standarttır. ${ }^{2}$ Uç-uca periferik sinir onarımı: "epinöral sütür", "grup fasiküler sütür" ya da "tek tek fasiküler sütür" gibi birkaç farklı yöntemle yapılabilir.

\section{Sinir Greftleri \\ Otojen sinir grefti}

Uç-uca onarımın mümkün olmadığı periferik sinir yaralanmalarında en yaygın olarak kullanılan teknik otojen sinir greftleri ile onarımdır. Donör greftin, gerginlik olmaması için alıcı bölgeden \%20 daha uzun kesilmesi önerilmektedir. ${ }^{29}$ En sık kullanılan otojen sinir greftleri:

- Sural sinir: Klinik uygulamada en sık kullanılan otojen sinir grefti olup inferior alveolar sinirle çapı neredeyse aynıdır. Uzunlamasına bir insizyon yada küçük transvers insizyonlarla $30-50 \mathrm{~cm}$ arası boyutlarda greft alınabileceği bildirilmiştir. ${ }^{30,31}$ 
- Medial-lateral antebrakial kutanöz sinir: Medial antebrakial kutanöz sinirden $10 \mathrm{~cm}$, lateral antebrakial kutanöz sinirden 20 cm'ye kadar sinir grefti elde edilebilir. ${ }^{32}$

- Büyük Aurikular Sinir: Kontrol ettiği alan sınırlıdır ve donör bölge his kaybı sonrası rahatsızlık çok azdır. Mandibulektomi sırasında aynı insizyon hattını kullanarak sinire ulaşılabilir. $10 \mathrm{~cm}$ e kadar greft almak mümkündür. ${ }^{29}$

Vaskülarize sinir grefti: Sinir defektinin büyük ya da alıcı alan kanlanmasının kötü olduğu durumlarda vaskülarize sinir greftlerinin kullanılabilir ancak, eşlik eden arter ince olduğunda teknik olarak uygulama güçlüğü, büyük arterlerin harcanma ihtimali gibi sebeplerle klinik kullanımı oldukça kısıtlıdır. ${ }^{33}$

\section{Entübülasyon}

Ayrılan sinir uçları arasındaki akson rejenerasyonuna rehberlik etmek amacıyla; sinir uçlarına otojen veya alloplastik kaynaklı tüp bağlanması olarak tarif edilebilir. $30 \mathrm{~mm}$ nin altındaki kısa periferal sinir defektlerinde endike olduğu bildirilmiştir. ${ }^{34}$ Otojen kaynaklı entübülasyon gereçleri; ven, kollajen, kas ve fasyalardır. Alloplastik kaynaklı entübülasyon gereçlerinden popüler olanları ise; politetrafloroetilen (goretex), silikon ve polyglikolik asit (neurotube) sayılabilir. ${ }^{2}$ Silikon; beş mm'nin altındaki defektlerde başarılı sonuç vermektedir ancak meydana gelebilen yabancı cisim reaksiyonu nedeniyle 1-2 mm ebatındaki küçük defektlerde kullanılmasını öneren yayınlar mevcuttur. ${ }^{35}$ Politetrafloroetilen üst eksterimetede başarılıdır, ancak inferior alveolar ve lingual sinir onarımı sonrasında, bu yöntemle iyileşmenin yeterli olmadığı gözlemlenmiştir. ${ }^{35}$

\section{Düşük Doz Lazer Tedavisi}

Düşük doz lazer tedavisinin (DDLT), cerrahi müdahele olmadan sinir stimulasyonu yaparak, sinir yaralanması sonrası oluşan rejeneratif süreci hızlandırdığı düşünülmektedir. ${ }^{36-39}$. Özen ve ark. inferior alveolar sinire yakın 3. molar çekimleri sonucu parestezi şikayeti olan hasalarda, paresteziden 18 ay sonra uygulanan DDLT tedavisinin sinir fonksiyonlarında ve myelin kapasitesinde artışa yol açtığını belirtmişlerdir. ${ }^{40}$ Benzer şekilde Führer-Valdivia et al. saggital split osteotomisi sonrası sinir hasarı bildiren 17 deney grubu hastası ve 14 kontrol grubu hastalarında yapılan randomize kontrollü çalışmalarında; DDLT'nin inferior alveolar sinir iyileşmesinde başarılı sonuç verdiğini açıklamışlardır. ${ }^{41}$

\section{SONUÇ}

Diş hekimliğinde klinik uygulamalar sırasında oluşan periferik sinir yaralanmaları enjeksiyon yaralanmaları ve kök kanal dolgusu komplikasyonları dışında genel olarak Ağız Diş ve Çene Cerrahisi branşını ilgilendirmektedir. Hasar meydana geldiği zaman önemli olan, her hastayı bireysel bazda ele alarak, yaralanmanın derecesini ve uygulanacak tedavileri hızlı bir şekilde değerlendirmek ve uygulamaktır.

\section{KAYNAKLAR}

1. Aydın S. Human anatomy ve phisyology. T.C.Anadolu Üniversitesi Yayını: Açıöğretim Fakültesi Yayını. Eskişehir: 2000. p: 85.

2. Miloro, M. In: Peterson' Principles of Oral and Maxillofacial Surgery. $2^{\text {nd }}$ ed. Hamilton: BC Decker; 2004. ch:41.

3. Seddon HJA. Classification of Nerve Injuries. Brit Med J 1942;2: 237-9.

4. Sunderland SA Classification of peripheral nerve injuries producing loss of function. Brain: J of Neurology 1951;74:491-516.

5. Smith $\mathrm{MH}$, Lung KE. Nerve injuries after dental injection: a review of the literature. J Can Dent Assoc 2006; 72: 559-64.

6. Andreasen JO. The impacted premolar. In: Andreasen JO, Petersen JK, Laskin DM, editors. Textbook and color atlas of tooth impactions; diagnosis, treatment and prevention. Copenhagen: Munksgaard; 1997. p. 177-95.

7. Uygun S, Apaydın A. Pheripheral Nerve Injuries And Treatments in Maxillofacial Region. İ. Ü. Diş Hek Fakültesi Dergisi 2008;42:11-7.

8. Hu J, Zou S, Tang Z, Wang D, Li J, Gao Z. Response of Schwann cells in the inferior alveolar nerve to distraction osteogenesis: an ultrastructural and immunohistochemical study. Int j oral maxillofac surg 2003;32:318-24.

9. Andrabi SM, Alam S, Zia A, Khan MH, Kumar A. Mental nerve paresthesia secondary to initiation of endodontic therapy: a case report. Restor Dent Endod 2014;39:215-9.

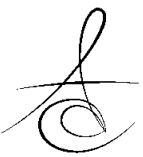


10. Moon S, Lee SJ, Kim E, Lee CY. Hypoesthesia after IAN block anesthesia with lidocaine: management of mild to moderate nerve injury. Restor Dent Endod 2012;37:232-5.

11. Knowles KI, Jergenson MA, Howard JH. Paresthesia associated with endodontic treatment of mandibular premolars. J Endod 2003;29:76870.

12. Fanibunda K, Whitworth J, Steele J. The management of thermomechanically compacted gutta percha extrusion in the inferior dental canal. Br Dent J 1998;184:330-2.

13. Shavit I, Juodzbalys G. Inferior alveolar nerve injuries following implant placement - importance of early diagnosis and treatment: a systematic review. J Oral Maxillofac Res 2014;5:e2.

14. Gokkulakrishnan S, Singh S, Sharma A, Singh AK, Borah R. Facial nerve injury following surgery for temporomandibular joint ankylosis: a prospective clinical study. Indian J Dent Res 2013;24:521.

15. González-García $\mathrm{R}^{1}$, Rodríguez-Campo FJ, EscorialHernández V, Muñoz-Guerra MF, Sastre-Pérez J, Naval-Gías L, Gil-Díez Usandizaga JL. Complications of temporomandibular joint arthroscopy: a retrospective analytic study of 670 arthroscopic procedures. J Oral Maxillofac Surg 2006;64:1587-91.

16. Blackburn CW. A method of assessment in cases of lingual nerve injury. British J Oral Maxillofacial Surg 1990;28:238-45.

17. Ghali EG, Epker BN. Clinical neurosensory testing: practical applications. J Oral Maxillofacial Surg 1989;47:1074-8.

18. Lambert GA, Mallos G, Zagami A S. Von Frey's hairs - a review of their technology and use - a novel automated von Frey device for improved testing for hyperalgesia. J Neurosci Meth 2009;177:420-6.

19. Chan AW, MacFarlane IA, Bowsher D, Campbell JA. Weighted needle pinprick sensory thresholds: a simple test of sensory function in diabetic peripheral neuropathy. J Neurol Neurosurg Psychiatry 1992;55:56-9.

20. Güneş Y, Mert T,Özcengiz D, Günay İ. The Role of N-Methyl D-Aspartate Receptors on Pain Transmission. Cukurova Med J 2012;37:9-16.

21. Greenwood M, Corbett I P. Observations on the exploration and external neurolysis of injured inferior alveolar nerves. Int J Oral Maxillofacial Surg 2005;34:252-6.

22. Chhabra A, Ahlawat S, Belzberg A, Andreseik G. Peripheral nerve injury grading simplified on $M R$ neurography: As referenced to Seddon and Sunderland classifications. Indian J Radiol Imaging 2014;24:217-24.

23. Cornwall R, Radomisli TE. Nerve injury in traumatic dislocation of the hip. Clin Orthop Relat Res 2000; 377: 84-91.

24. Seo K, Tanaka Y, Terumitsu M, Someya G. Efficacy of steroid treatment for sensory impairment after orthognathic surgery. J Oral Maxillofac Surg 2004;62:1193-7.

25. Lee HY, Byun JY, Park MS, Yeo SG. Steroidantiviral Treatment Improves the Recovery Rate in Patients with Severe Bell's Palsy. Am J Med 2013;126:336-41.

26. Nazario J, Kuffler DP. Hyperbaric oxygen therapy and promoting neurological recovery following nerve trauma. Undersea Hyperb Med. 2011;38:345-66.

27. Toros SZ, Karaca ÇT, Güneş $P$, Oysu Ç, Ertugay ÇK, Naiboğlu B, Elbüken E, Egeli E. Hyperbaric oxygen versus steroid in facial nerve injury: an experimental animal study. Am J Otolaryngol 2013;34:530-6.

28. Joseph G. McCarthy Plastic Surgery. 3rd ed. Hardcover: W.B. Saunders Company; 1990. Vol 1.

29. Takasaki YN, Kitami T, Shibahara T, Sasaki K. Reconstruction of the inferior alveolar nerve by autologous graft: a retrospective study of 20 cases examining donor nerve length. Bull Tokyo Dent Coll 2003;44:29-35.

30. Terenghi G. Peripheral nerve regeneration and neurotrophic factors. J Anat 1999;194:1-14.

31. Poppler LH, Davidge K, Lu JC, Armstrong J, Fox IK, Mackinnon SE. Alternatives to sural nerve grafts in the upper extremity. Hand (N Y). 2015;10:68-75

32. Shibahara T, Noma H, Takasaki Y, Nomura T. Repair of the inferior alveolar nerve with a forearm cutaneous nerve graft after ablative surgery of the mandible. J Oral Maxillofac Surg 2000;58:714-7.

33. Zhu Y, Liu S, Zhou S, Yu Z, Tian Z, Zhang C, Yang W. Vascularized versus nonvascularized facial nerve grafts using a new rabbit model. Plast Reconstr Surg 2015;135:331e-9e. 
34. Schlosshauer B, Dreesmann L, Schaller HE, Sinis N. Synthetic nerve guide implants in humans: $A$ comprehensive survey. Neurosurgery 2006;59: 740-7.

35. Battiston B, Geuna S, Ferrero M, Tos P. Nerve repair by means of tubulization: literature review and personal clinical experience comparing biological and synthetic conduits for sensory nerve repair. Microsurgery 2005;25:258-67.

36. Mohammed IF, Al-Mustawfi N, Kaka LN. Promotion of regenerative processes in injured peripheral nerve induced by low-level laser therapy. Photomed Laser Surg 2007;25:107-11.

37. Gigo-Benato D, Geuna S, Rochkind S. Phototherapy for enhancing peripheral nerve repair: a review of the literature. Muscle \& nerve 2005;31:694-701.

38. Tarhan K, Alkan BA. Periodontal Tedavide Düşük Doz Lazer Tedavisi Uygulamaları. Atatürk Üniv Diş Hek Fak Derg 2014;24:61-6.

39. Mester AF, Snow JB, Shaman P. Photochemical effects of laser irradiation on neuritic out growth of olfactory neuroepithelial explants. Otolaryngol Head Neck Surg 1991;105: 449-56.

40. Ozen T, Orhan K, Gorur I, Ozturk A. Efficacy of low level laser therapy on neurosensory recovery after injury to the inferior alveolar nerve. Head Face Med 2006;2:3.

41. Fuhrer-Valdivia A, Noguera-Pantoja A, RamirezLobos V, Sole-Ventura P. Low-level laser effect in patients with neurosensory impairment of mandibular nerve after sagittal split ramus osteotomy. Randomized clinical trial, controlled by placebo. Med Oral Patol Oral Cir Bucal 2014;19: 327-34.

\section{Yazışma Adresi}

Yrd. Doç. Dr. Nilay ER, DDS, PhD

Trakya Üniversitesi Diş Hekimliği Fakültesi, Ağız Diş ve Çene Cerrahisi AD, Edirne, Türkiye Tel: 0905327012062

Fax: 090 (284) 236455

e-mail: nilayer@trakya.edu.tr 